|| ISSN(online): 2589-8698 || ISSN(print): 2589-868X ||

International Journal of Medical and Biomedical Studies

Available Online at www.ijmbs.info

NLM (National Library of Medicine ID: 101738825)

Index Copernicus Value 2019: 79.34

Original Research Article

Volume 5, Issue 9; September: 2021; Page No. 17-20

\title{
CLINIC OPATHOLOGICAL STUDY OF COLORECTAL MALIGNANCY IN TERTIARY CARE HOSPITAL
}

\author{
${ }^{1}$ Dr. Ravindra Singh, ${ }^{2} \mathrm{Dr}$ Atul Ameta \\ ${ }^{1,2}$ M S General Surgery \\ ${ }^{1}$ Department of Surgery, RNT Medical College and Maharana Bhupal Govt. Hospital, Udaipur \\ ${ }^{2}$ Assistant Professor, RNT Medical College and Maharana Bhupal Govt. Hospital, Udaipur
}

Article Info: Received 02 July 2021; Accepted 20 August 2021

DOI: https://doi.org/10.32553/ijmbs.v5i9.2175

Corresponding author: Dr Atul Ameta

Conflict of interest: No conflict of interest.

\begin{abstract}
Background: Colorectal carcinoma is one of the most frequent malignancies in the world. It is the second foremost cause of cancer mortality in the United States.

Methods: The present study was carried out on 25 patients, being admitted to the various surgical wards ofM.B. Govt. Hospital, attached to the R.N.T. Medical College Hospital, Udaipur between the period July 2017 to November 2019

Results: The presenting symptoms in the present study were change in bowel habit (92\%), bleeding per rectum (32\%), and loss of weight in $60 \%$ of cases. A lump abdomen was noticed in $48 \%$ of cases, pain abdomen in $36 \%$ of cases. $16 \%$ presented with acute bowel obstruction.

Conclusion: The common symptoms of constipation or constipation with diarrhoea are neglected and treated with simple laxative without elaborate investigation. Bleeding from malignant growth in the rectum is thought to be from piles and mistreated accordingly, without doing a simple digital examination. It is emphasized that a thorough history taking, proper physical examination is must. To arrive in a correct diagnosis and plan a definite treatment. Also health education to the public in the forms of lectures, posters and audio-visual presentations will help the patient to seek medical advise at an earliest time.
\end{abstract}

Keywords: Colorectal, Carcinoma, Clinical

\section{Introduction}

Colorectal carcinoma is one of the most frequent malignancies in the world. It is the second foremost cause of cancer mortality in the United States. Hence, colorectal cancer poses a severe concern to public health ${ }^{1}$

Compared to the western world, the incidence rates of colorectal cancer are low in India; but apart from geographical variations, the incidences are rising rapidly in India. Incidence rate in different subsides varies for age, gender, and race ${ }^{2}$

Colorectal cancer is the third most common cancer in men (746,000 cases, $10.0 \%$ of the total) and the second in women $(614,000$ cases, $9.2 \%$ of the total) worldwide. Almost 55\% of the cases occur in more developed regions. There is wide geographical variation in incidence across the world and the geographical patterns are very similar in men and women ${ }^{3}$

\section{Materials and Methods}

Cases of colorectal carcinoma were collected from July 2017 to November 2019 for this study. A total of 25 cases were studied of which 8 cases presented as emergencies.

Detailed history was elicited from each patient with special reference to family history, habitations and early symptomatology. Thorough physical examination of the patient was performed for evaluation of general condition, detection of signs and per-rectal examination.

Thorough laboratory investigations were done in all patients and majority of underwent USG abdomen. Luminal contrast radiographic studies were done in selected cases. Colonoscopy and CT scan abdomen and pelvis was done in majority of cases. Chest skiagram taken for all patients for preoperative evaluation as well as detection of secondaries. Liver function test was done as routine investigation in all patients.

For all possible cases, preoperative biopsy taken via proctoscopic, colono scopic guidance and histologic type made out before planning treatment. Detailed histopathological reports were available for staging of tumour and assessing the grade of differentiation.

\section{Results}

The present study was carried out on 25 patients, being admitted to the various surgical wards of M.B. Govt. Hospital, attached to the R.N.T. Medical College Hospital, Udaipur between the period July 2017 to November 2019 
Most of the cases were from older age group. Maximum incidence was in the sixth decade, but even below the age of 30,5 cases were reported. The tendency to develop colorectal carcinoma is considered to increase progressively with advancing age. But incidence is also increasing in adults younger than 40 years. Incidence was relatively more in females. M: $\mathrm{F}$ ratio in this series was 0.92:1 .

Majority of the patients though had symptoms for some time, tend to ignore them and presented at latest ages.

Eight out of 25 cases (32\%) in this series are presented as acute emergencies. Twelve cases presented with obstructive features, Out of them 4 were presented in emergency setting with acute bowel obstruction

Majority of the cases (84\%) had symptoms of altered bowel habits and anaemia (84\%). Weight loss was present in $60 \%$ cases, lump abdomen was present in 12 patients $48 \%$ cases, 3 cases of recto sigmoid growth, 3 cases of ascending colon, 2 cases of hepatic flexure growth, 2 cases of sigmoid colon, 1 case of descending colon and 1 case of caecum, and pain abdomen was present in $36 \%$ cases. Bleeding per rectum were seen $32 \%$ cases.

Table 1: Colorectal carcinoma sign and symptoms in this series

\begin{tabular}{|c|c|c|c|c|c|c|c|}
\hline No. of Cases & R.Colon & L.Colon & Trans. Colon & $\begin{array}{l}\text { Sigmoid } \\
\text { Colon/Rectosigmoid } \\
\text { junction }\end{array}$ & $\begin{array}{l}\text { Rectum/Anal } \\
\text { Canal }\end{array}$ & Total & Percentage \\
\hline No. of cases & 9 & 6 & 0 & 8 & 2 & 25 & $100 \%$ \\
\hline \multicolumn{8}{|l|}{$\begin{array}{l}\text { Signs / } \\
\text { symptoms }\end{array}$} \\
\hline Pain & 4 & 1 & 0 & 3 & 1 & 9 & $36 \%$ \\
\hline $\begin{array}{l}\text { Altered bowel } \\
\text { Habits }\end{array}$ & 7 & 5 & 0 & 7 & 2 & 21 & $84 \%$ \\
\hline $\begin{array}{l}\text { Bleeding per } \\
\text { Rectum }\end{array}$ & 0 & 0 & 0 & 6 & 2 & 8 & $32 \%$ \\
\hline $\begin{array}{l}\text { Mucus per } \\
\text { Rectum }\end{array}$ & 0 & 2 & 1 & 4 & 1 & 8 & $32 \%$ \\
\hline $\begin{array}{l}\text { Lump } \\
\text { abdomen }\end{array}$ & 6 & 3 & 0 & 3 & 0 & 12 & $48 \%$ \\
\hline Weight Loss & 6 & 4 & 0 & 4 & 1 & 15 & $60 \%$ \\
\hline Anemia & 8 & 3 & 0 & 8 & 2 & 21 & $84 \%$ \\
\hline $\begin{array}{l}\text { Acute } \\
\text { obstruction }\end{array}$ & 1 & 1 & 0 & 2 & 0 & 4 & $16 \%$ \\
\hline Peritonitis & 0 & 0 & 0 & 0 & 0 & 0 & $0 \%$ \\
\hline
\end{tabular}

Altered bowel habits, anaemia and weight loss were the significant symptoms in our series. $84 \%$ of the patients presented with altered bowel habits and anemia while $60 \%$ of the patients gave history of significant weight loss.

Most of the recto sigmoid and left sided growth were either annular and stenosing or ulcerative with infiltration type. Almost all cases of carcinoma rectum were of ulcerative type. 3 sigmoid growths showed infiltration into surrounding viscera. One case of anorectal carcinoma presented within filtration of prostate. One patient presented with $\mathrm{B} / \mathrm{L}$ hydronephrosis due to ureteric compression. Majority of right sided growths were polypoidal or cauliflower like growths. One hepatic flexure growth was found to infiltrate into abdominal wall. Two cases of synchronous tumour found, one was synchronous carcinoma of caecum and sigmoid colon growth. While the other was carcinoma of second part of duodenum and carcinoma of hepatic flexure. 5 patients presented with distant metastasis. Out of them 3 had multiple liver metastasis, one had dorsolumbar spine metastasis. One patient present with peritoneal metastasis in the form of nodules.

\section{Staging}

Histopathological staging was carried out on resection specimen and the results were obtained. No case presented in Duke Stage A $(0 \%), 2$ were in Stage B $(16.67 \%), 3$ were Stage $\mathrm{C}_{1}(25 \%), 2$ were stage $\mathrm{C}_{2}(16.67 \%)$, and 5 cases presented in stage $\mathrm{D}(41.66 \%)$. 
Table 2: Staging

\begin{tabular}{|c|c|c|c|c|}
\hline Stage & Male & Female & Total & Percentage \\
\hline A & 0 & 0 & 0 & $0 \%$ \\
\hline $\mathrm{B}$ & 1 & 1 & 2 & $16.67 \%$ \\
\hline $\mathrm{C}_{1}$ & 2 & 1 & 3 & $25 \%$ \\
\hline $\mathrm{C}_{2}$ & 1 & 1 & 2 & $16.67 \%$ \\
\hline $\mathrm{D}$ & 3 & 2 & 5 & $41.66 \%$ \\
\hline Total & 7 & 5 & 12 & $100 \%$ \\
\hline
\end{tabular}

Maximum percentage of cases (41.66\%) was Dukes's classification stage D.

Table 3: Distribution of Patients according to TNM Staging

\begin{tabular}{|l|l|l|l|l|l|}
\hline S. No. & Stage & Male & Female & Total & Percentage \\
\hline 1. & 0 & 0 & 0 & 0 & $0 \%$ \\
\hline 2. & I & 0 & 0 & 0 & $0 \%$ \\
\hline 3. & IIA & 1 & 1 & 2 & $8.69 \%$ \\
\hline 4. & IIB & 1 & 1 & 2 & $8.69 \%$ \\
\hline 5. & IIIA & 0 & 0 & 0 & $0 \%$ \\
\hline 6. & IIIB & 6 & 4 & 10 & $43.47 \%$ \\
\hline 7. & IIIC & 1 & 3 & 4 & $17.4 \%$ \\
\hline 8 & IV & 3 & 2 & 5 & $21.71 \%$ \\
\hline
\end{tabular}

1. Stage $\mathrm{I}=$ zero

2. Stage IIA $=2$ cases

3. Stage $\mathrm{IIB}=2$ cases

4. Stage IIIA = Zero

5. Stage IIIB $=10$

6. Stage IIIC $=4$

7. Stage $\mathrm{IV}=5$

In these study maximum cases presented in III B stage (43.47\%).

Moderately differentiated tumour predominated. 12 out of 25 cases belonged to this (48\%) 7 cases were well differentiated $(28 \%)$ and 6 cases were poorly differentiated (24\%) type.

Table 4: Grading

\begin{tabular}{|l|l|l|l|l|}
\hline Grade & Male & Female & Total & Percentage \\
\hline Grade I & 4 & 3 & 7 & $28 \%$ \\
\hline Grade II & 6 & 6 & 12 & $48 \%$ \\
\hline Grade III & 2 & 4 & 6 & $24 \%$ \\
\hline Total & $\mathbf{1 2}$ & $\mathbf{1 3}$ & $\mathbf{2 5}$ & $\mathbf{1 0 0 \%}$ \\
\hline
\end{tabular}

Predominance of moderately differentiated carcinoma can be seen.

\section{Discussion}

Malignancy of the large bowel form one of the common types of cancer, whichpresent with different clinical symptoms and signs. In our country because of ignorance, illiteracy, low socio-economic status and feeling of fear of colostomy, most of the patient present late in the advanced stage, where only palliative treatment can be offered. Also these cases presenting with bleeding per-rectum were treated as piles by general family practitioner, till no relief was obtained by conventional method and then referred to teaching institute. Also the incidence of malignancy in general and malignancy of large bowel particular is becoming more due to increasing life span of the people.

The commonest presenting symptom in the present study was change in bowel habit (84\%) and anaemia (84\%), followed by loss of weight $(60 \%)$. Common symptoms include abdominal pain, rectal bleeding, anaemia, altered bowel habits, and involuntary weight loss. Symptoms depend on cancer location, cancer size, and presence of metastases (Bond, 2000).

The symptomatology in carcinoma of colon and rectum has been well established. A change in the bowel habit, in the form of diarrhoea, constipation or absolute constipation was present in $84 \%$ percent cases in the present study. A change in bowel habit of increasing constipation was an important feature. Many patients did not take any notice of it until they developed subacute intestinal obstruction. Change in bowel habit dominate the colonic carcinoma of the left side. Other workers have also expressed similar views. ${ }^{4}$ Diarrhoea occurred more often with right-sided growthsas also observed in the present study.

Weight loss of a significant degree was the next common symptom, present in $60 \%$ cases in the present work. Palumbo LT et al (1953) reported an incidence of weight 
loss of $66.25 \%$ and Fletcher W.J. et al. (1953) of 38\% in their studies.

Bleeding per rectum has been reported as the most common symptom in carcinoma of rectum and rectosigmoid by Brindley G.V. et al. (1937); in our study bleeding per rectum was a significant symptom in 8 patients $(32 \%)$.

\section{Conclusion}

It is concluded from the present study that patients suffering from malignancy of large bowel, particularly of rectum and rectosigmoid region present for radical treatment in an advanced stages, where possibility of medical resection are very little. The common symptoms of constipation or constipation with diarrhoea are neglected and treated with simple laxative without elaborate investigation. Bleeding from malignant growth in the rectum is thought to be from piles and mis-treated accordingly, without doing a simple digital examination. It is emphasized that a thorough history taking, proper physical examination is must. To arrive in a correct diagnosis and plan a definite treatment. Also health education to the public in the forms of lectures, posters and audio-visual presentations will help the patient to seek medical advise at an earliest time.

\section{References}

1. Aakif M, Balfe P, Elfaedy O, Awan FN, Pretorius F, Silvio L, Castinera C, Mustafa H.Study on colorectal cancer presentation, treatment and follow-up. Int J Colorectal Dis. 2016 Jul; 31(7):1361-3. doi: 10.1007/s00384-015-2479-0. Epub 2016 Jan 7.

2. AJCC Cancer Staging Manual, $6^{\text {th }}$ Edition, New York, 2002.

3. Allum WH et al. Cancer of the colon and rectum in the West Midlands. 1957-81. Br J Surg1994; 81:1060-3.

4. Chapuis $\mathrm{PH}$ et al. A multivariate analysis of clinical and pathological variables in prognosis after resection of large bowel cancer. Br. J. Surg. 1985; 72:698-702.

5. Palumbo L.T. et al. Cancer of the colon and rectum. Analysis of 300 cases. Am. J. Surg. 109 : 439-44, 1965

6. Ferlay J, Shin HR, Bray F, Forman D, Mathers C, Parkin DM. Estimates of worldwide burden of cancer in 2008: GLOBOCAN 2008. Int J Cancer. 2010;127:2893-2917

7. Brindley et al. Carcinoma of rectum. JAMA 1937; 108:37. 